\title{
Research and Development of a New Electromechanochemical Method for the Activation of Mineral Binders
}

\author{
K.A. Bissenov
}

S.S. Uderbayev

\section{Doi:10.5901/mjss.2014.v5n20p2711}

\begin{abstract}
The article discusses the research and development of a new method for activating raw materials in the binder and concrete technology. An effective activation method was developed following an original technique. For these purposes, a research logic sequence was adopted: (a) idea, (b) principle, (c) method, and (d) device. A new special activator - a drum electropolarization mill was designed and constructed. Experiments on the mechanism of activation and the measurement of electrokinetic potential of the activated cementitious mixture were carried out. The optimum compositions of cement-ash mixture for the production of concrete and wood concrete were proposed.
\end{abstract}

Keywords: activation method, electromechanochemical, mill, strength, ash cement stone.

\section{Introduction}

The problem of improving the physical and mechanical properties of concrete is always a topical issue. Taking into account the technological waste during the composition of the building materials, its relevance undoubtedly increases. The importance of this issue is even more amplified with the constant increase in the volume of industrial waste-ash and slag of CHP. In addition, there is also the waste of renewable re-tonnage vegetable farming. Clearly, the solution to this problem provides not only economic, but also environmental benefits.

Experts in the field of building materials consider that the concrete in a cement binder will continue to be one of the main construction materials for many years. The increase in strength, density, corrosion resistance of cement-based materials allows extending the service of structures and reduces operating costs. In this regard, promising technologies are those built on the use of advanced methods of activation.

The matter of saving Portland cement is inextricably linked with the problem of a more rational use of the binder in the production of concrete with the desired properties. There is also the problem of multi-level structure formation. The solution should provide the basis for subsequent modifications of the structure of the cement stone and concrete. In this regard, the article addressed the issue of developing new and effective ways to activate poly-disperse systems and to disclose its mechanism of activation. Therefore, the quality of light concrete is improved.

Analysis of numerous works of domestic and foreign researchers on the issue of energy efficiency in the building industry shows that the energy-saving technology of building materials is under development in different areas of traditional technology improvement, in the creation of materials that consume less power, and in related technologies.

In this respect, the development and introduction of resource-saving technologies and the use of local raw materials and industrial waste in the production of construction materials are an important issue. However, existing technologies are not yet fully developed, and so the quality of certain products leaves much to be desired. Consequently, advanced research and the development of resource- and energy-saving technologies become imperative, where the emphasis is on reducing the flow rate of material and labor resources per unit of production without lowering or compromising the quality of the properties of building materials and products.

In his paper, I.A. Rybyev [1] notes that preparatory operations play an important role in disclosing the potential properties of raw materials for the construction of artificial conglomerates.

In other studies [2-7] considering the technological process as a complex system, it is necessary to take into account the internal and external interactions of the separate components of the system that will ultimately affect the response of the system (i.e., material properties, in particular, the strength of wood concrete). 


\section{Materials and Methods}

In carrying out the experimental research, the idea of creating the activation binder principle was primary, and the implementation of the principle, of course, led to a need of developing a method, that in turn, led to the design, implementation, and use of the device.

The experimental search was methodically built on the following logical sequence: (1) idea, (2) principle, (3) method, and (4) device.

Before determining the methods for the experimental studies, the following idea was laid in the framework: to use the advantages of the polarizability of binder particles under the electric field for additional binder activation.

To determine the $\zeta$-capacity by dissolving cement in water and in aqueous solutions of various chemical substances and mineral additives (in salt solutions of barium chloride and fly-ash), experiments via electrophoresis in accordance with the methodological developments were carried out [8]. Experiments on the measurement of electrokinetic potential were performed in the laboratory of the Department of Colloid Chemistry at the Al-Farabi Kazakh National University.

Given the complexity of experimental modeling of the system under study, we used a method of mathematical planning of the experiment. The basis of the design of experiments included the traditional methods in which each parameter of the investigated factor is computed separately. The varying factors in the research are temperature; the ratio $(A: B)$ and the duration of the pre-treatment of aggregate; chemical additives; water-binder ratio; and the duration and parameters (current, voltage) necessary for the conditions of electromechanochemical (EMC) processing of cementitious mixture. The main criterion for assessing the effectiveness of the investigated factors is a strength range under compression.

Statistical analysis of the results of the study was made in accordance with GOST 180115-72 (Concrete. Monitoring and evaluation of homogeneity and strength) of the definition of the arithmetic mean of strength, dispersion characteristics, the root mean variations, and the coefficient of variation $[9,10]$.

To create the highest electric field in the cement paste, the electrode structure was done in the form of plates made of a thin stainless metal, $0.5-\mathrm{mm}$ thick to increase the contact area with the cement paste. In the initial variant, the construction of electrodes was tried in the form of a mesh type, the wires of a circular cross-section steel. These types of electrodes did not give an EMC effect and did not increase the strength of the cement-ash stone. In addition, they were subjected to corrosion over time.

The electric field was created by the DC rectifier and the AC laboratory transformer. The numerical value of the parameters generated by the electric current was adopted in the range of 10 to $30 \mathrm{~V}$. To assess the effect of the chemical additives on the strength of the cement-ash stone at mechanoelectropolarization, treatment by manual method was used: sodium, calcium, and barium chlorides (Table 1). During the EMC activation, there was a trend toward increasing the electrical conductivity of the cement paste from 200 to $400 \mathrm{~mA}$.

\section{Results}

The adopted idea came to fruition with the implementation of the following principle: The effect of an additional activation of the particle can be achieved by its simultaneous effect by two factors: the electric field passing through the liquid phase and the grinding process. As a result, the "principle of electromechanochemical (EMC) activation" was realized [11]. The image interpretation of this principle is shown in Fig. 1.

The laboratory apparatus with the illustration of the electrical circuit is shown in Fig. 2. Simple simulation of the "principle of activation" was conducted for verification. 
3

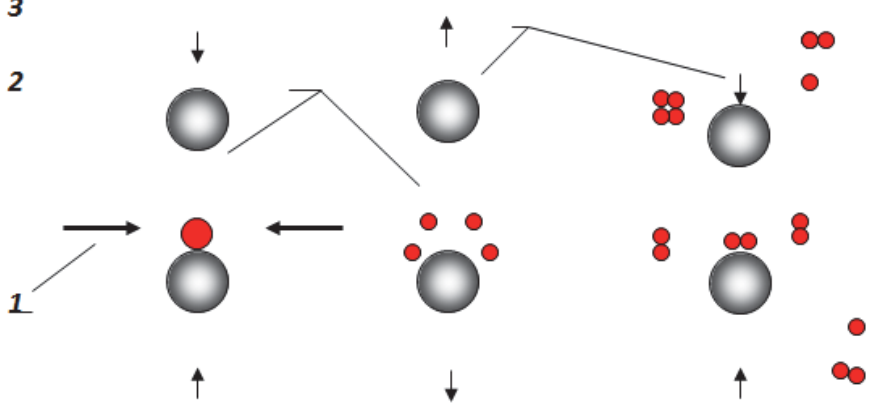

1 - the electric field effect through dispersion medium; 2 - the binder particles; and 3 - the grinding media.

Fig. 1. Schematic model of the principle of electromechanochemical activation of the binder (with the RK provisional patent No. $7101 \mathrm{~W})$.

The cement-ash composition of $\mathrm{C}: \mathrm{A}=60: 40$ for $\mathrm{W} / \mathrm{C}=0.6$ was adopted as the binder. The porcelain mortar with a capacity of 1 liter for passing an electric current through the cement slurry and a porcelain pestle for shredding were used. Shredding was a manual process due to abrasive and shock impact.

Table 1 - Effect of chemical additives in the EMC activation on the mechanical properties of cement-ash binder composition of $60: 40 \%$

\begin{tabular}{|c|c|c|c|c|c|c|c|}
\hline \multirow{2}{*}{$\begin{array}{l}\text { Chemical additives in \% of } \\
\text { binder weight }\end{array}$} & \multirow[t]{2}{*}{ W/C } & \multirow{2}{*}{$\begin{array}{l}\text { Grinding } \\
\text { time, min }\end{array}$} & \multirow[t]{2}{*}{ Electric field type } & \multirow[t]{2}{*}{ Voltage, V } & \multicolumn{3}{|c|}{$\begin{array}{l}\text { Test results of samples of cement-ash stone on } \\
\text { compressive strength, } \mathrm{kg} / \mathrm{cm}^{2} \text { in days }\end{array}$} \\
\hline & & & & & 7 & 14 & 28 \\
\hline \multirow{3}{*}{ No chemical additives } & \multirow{3}{*}{0,6} & \multirow{3}{*}{10} & - & - & 68 & 98 & 275 \\
\hline & & & & 25 & 87 & 109 & 298 \\
\hline & & & & 25 & 82 & 101 & 289 \\
\hline \multirow{3}{*}{$5 \%$ sodium chloride } & \multirow{3}{*}{0,6} & \multirow{3}{*}{10} & - & - & 88 & 180 & 296 \\
\hline & & & Direct current & 25 & 101 & 215 & 366 \\
\hline & & & Alternative current & 25 & 95 & 202 & 356 \\
\hline \multirow{3}{*}{$5 \%$ calcium chloride } & \multirow{3}{*}{0,6} & \multirow{3}{*}{10} & \begin{tabular}{|c|}
- \\
\end{tabular} & - & 90 & 196 & 308 \\
\hline & & & \begin{tabular}{|c|} 
Direct current \\
\end{tabular} & 25 & 110 & 229 & 396 \\
\hline & & & Alternative current & 25 & 105 & 223 & 387 \\
\hline \multirow{3}{*}{$5 \%$ barium chloride } & \multirow{3}{*}{0,6} & \multirow{3}{*}{10} & \begin{tabular}{|c|}
- \\
\end{tabular} & - & 98 & 204 & 324 \\
\hline & & & Direct current & 25 & 153 & 306 & 502 \\
\hline & & & Alternative current & 25 & 125 & 252 & 486 \\
\hline
\end{tabular}

As seen from Table 1, the process of the EMC activation proceeds most effectively by adding barium chloride. The durability of the ash-cement stone is increased by $50 \%$ compared with control samples without polarization.

Experimental verification of the nominated principle yielded reliable results. This was the basis for further development of the actual method based on advancing the principle.

In this regard, the next steps for the study were the development and improvement of the specific process of EMC activation and the structure of the device to implement this method. At the same time, the electrical circuit of the EMC activation shown in Fig. 2 served as a the method's model of the shredder device [12,13] (laboratory mill of special design).

Based on the audit of the experimental results on the nominated principle of activation, a specific method for binder activation has been developed: combining the two operations (grinding processes and electric polarization) and carried out in a ball mill.

Electrolyte-barium chloride increased the electrical conductivity of cement paste, as well as contributed to effective dispersion to increase the electrical conductivity of the system "binder + water". At the same time, barium chloride plays the role of coagulant-initiator (i.e., electrocoagulant) of the physico-chemical process of cementitious mixture coagulation 
[11].

Note that the construction of a specially designed laboratory mill for the EMC effect is required. Among existing shredder designs, a choice was made on the structure of the ball mill. However, to make the ball mill work on the effect of polarization, it was necessary to modernize the mill construction.

In the initial version, the inner ball mill was covered with a thin layer of dielectric and installed steel stick electrodes. Over time, the dielectric layer was destroyed and the electrodes were subjected to corrosion.

The main requirement for the design of the mill is the mill housing which must be of a dielectric material. The electrodes are made of stainless steel with possibly low resistance required for the efficient flow of electric current through the dispersion medium.

Table 2 shows the tensile test data from the cement samples threshed by the proposed method in a drum electropolarization mill [11].

For the processes of EMC activation method in a drum electropolarization mill, a circuit diagram was assembled as shown in Fig. 2. The electric field is created by the current sources (rectifying devices and laboratory transformers), and that the applied voltage is adjustable.

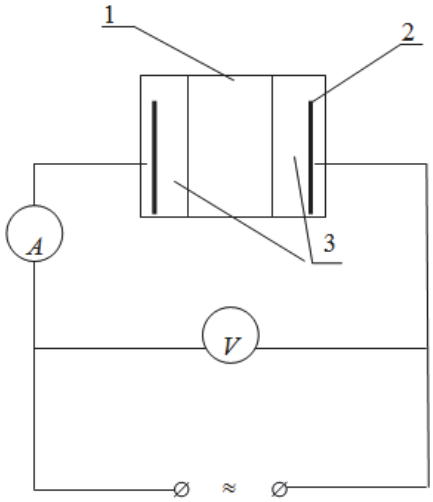

Fig. 2. Schematic diagram of the method of polarization of the cement binder inside the drum electropolarization mill. 1 the mill body made of a dielectric material; 2 - stainless steel electrodes as circular plates; and 3 - vertical walls with the sidewall.

The composition of the EMC binder awarded a prior patent [9] comprises Portland cement in an amount of 52-60\%, fly ash: $37-42 \%$, and barium chloride: $3-6 \%$ by weight. Herewith, barium chloride performs the role of the initiator of physical and chemical processes of coagulation of the cementitious mixture. During electrocoagulation, there is a polarization of the dispersed binder particles and there is mutual attraction that enhances the process of structure formation.

It is known that increasing the reactivity of the binder components in wet final grinding is achieved not only by increasing dispersion in the liquid phase, but also by changing the crystal structure, particle shape that is a prerequisite for intensifying the coagulation of cement-fly ash mixture. In this case, the chemical and mineralogical composition of the initial binding remains unchanged.

Table 2 - Effect of the electric field in the wet final grinding of cement-ash binder

\begin{tabular}{|c|c|c|c|c|c|c|c|c|}
\hline $\begin{array}{l}\text { No. } \\
\mathrm{p} / \mathrm{p}\end{array}$ & Binder composition & $\begin{array}{c}\text { Amount of } \\
\text { chemical } \\
\text { additive }\end{array}$ & $\begin{array}{c}\text { Type of } \\
\text { electric field }\end{array}$ & $\begin{array}{c}\text { Water-solid } \\
(\mathrm{W} / \mathrm{S}) \text { ratio }\end{array}$ & $\begin{array}{c}\text { Specific } \\
\text { surface of } \\
\mathrm{CAB}, \mathrm{cm} / \mathrm{g}\end{array}$ & $\begin{array}{c}\text { Duration of } \\
\text { wet grinding, } \\
\text { min }\end{array}$ & $\begin{array}{c}\text { Voltage, } \\
\mathrm{V}\end{array}$ & $\begin{array}{c}\text { Compressive } \\
\text { strength, } \mathrm{kg} / \mathrm{cm}^{2}, \text { at } \\
28 \text { days }\end{array}$ \\
\hline $\begin{array}{c}\text { Cement: fly ash of } \\
60: 40 \% \text { by weight }\end{array}$ & $\begin{array}{c}\mathrm{BaCl} 5 \% \text { by } \\
\text { weight of binder }\end{array}$ & - & 0,6 & 2750 & - & - & 345 \\
\hline & $-\ll-$ & $-\ll-$ & $-\ll-$ & 0,6 & 4225 & 30 & - & 375 \\
\hline$-\ll-$ & $-\ll-$ & $\begin{array}{c}\text { Alternative } \\
\text { current }\end{array}$ & 0,6 & 4650 & 30 & 30 & 538 \\
\hline & $-\ll-$ & $-\ll-$ & 0,6 & 4705 & 30 & 40 & 546 \\
\hline & $-\ll-$ & $-\ll-$ & $\begin{array}{c}\text { Direct } \\
\text { current }\end{array}$ & 0,6 & 4820 & 30 & 30 & 562 \\
\hline
\end{tabular}


Table 2 shows that under this method of activation, the strength of the binder is increased by $50-60 \%$, respectively, with the voltage of 30-40 V weight in the binder of a mixture. In the electric field of the DC, the EMC process of activation of cement-ash binder particles is better than the $\mathrm{AC}$ one.

The formation of electric double layer (EDL) of ions leads to an electrokinetic ( $\zeta$-zeta) potential at the particle boundary of binder and water [8]. The introduction of barium chloride - electrolyte alters the structure of EDL, that is, a compression of its diffused layer and depression of zeta potential values. In fact, $\zeta$-potential is involved in the formation of the coagulation structure of the cement gel; it defines the essence of electrokinetic phenomena (related to electrical conductivity of the cement gel) and physico-chemical processes that lead to the formation of crystalline hydrate structure of cement-ash stone $[14,15]$.

The intensification of the coagulation process of the binder occurs by combining the phenomenon of increasing the specific surface area of the particles and the effect of reducing the zeta potential and the homogenization of EDL charges.

The activation mechanism of cement-fly ash mixture by EMC impact is through effectively opening the potential properties of the binder particles with the effect of the specific surface increase and simultaneously passing an electric current to the inner portions of ground particles. As a result, it enhances the grinding process, increasing the reactivity and activity of the binder.

In the proposed apparatus [1], one of the conditions for enhancing the binding properties of the raw components is the polarization of particles during grinding, leading to the active interaction of activated disperse binder particles. Proceeding from the foregoing, it follows that the mechanism of activation for the EMC method is in electrical interaction of re-exposed surfaces of the binder particles in wet final grinding, that is, imparting an electric charge to each particle.

To prove the increased activity of the binder at the EMC effect, the actions on measuring the zeta potential of the activated mixture were performed. Thereby, the cementitious mixture without processing, and after the wet final grinding and the EMC activation were sampled (Table 3).

Table 3 - Measurement of electrokinetic potential

\begin{tabular}{|c|l|c|c|c|c|}
\hline No. & Composition of The material (\%) & Type of activation & Amount of chemical additive & $\begin{array}{c}\text { Time } \\
\tau, \text { second }\end{array}$ & $\begin{array}{c}\zeta \text { - potential, } \\
\mathrm{mV}\end{array}$ \\
\hline 1. & Cement: fly ash (60:40) & No processing & - & 41,3 & 42,2 \\
\hline 2. & Cement: fly ash (60:40) & Wet final grinding & $5 \%$ of $\mathrm{BaCl} 2$ of the total mass binder & 54,4 & 32 \\
\hline 3. & Cement: fly ash (60:40) & EMC & $\begin{array}{c}5 \% \mathrm{BaCl}_{2} \\
-\ll-\end{array}$ & 57,9 & 30,1 \\
\hline
\end{tabular}

Table 3 shows that at the EMC activation, the $\zeta$-potential of the binder is less compared with the final grinding one and without wet processing that affects the increase in activity, therefore, the strength of the cement-ash stone and wood concrete based on it. The reduction of the zeta potential is due to the greater interaction of multiplied charged anions with negative charges, i.e., products of the binder hydration and the transition of opposite-charged ions from the diffuse layer into the adsorption one. Moreover, apparently, the reduction of $\zeta$-potential promotes a partial amorphization of the surface of the activated binder [16].

Note also the decrease of zeta potential ( $\zeta$-potential) that speeds up the process of cementitious mixture coagulation and affects the strength enhancement of the cement-ash stone.

\section{Discussion}

The effect of the electric field during the wet final grinding leads to an intensification of ion exchange processes due to the increase of the micelle-forming particles with a specific charge of atoms, molecules, and ions in the element volume. The polarizability of the ions due to the electric field leads both to an enhancement of electric charges that increases the activity of their transport and to a rearrangement of released electrons and ions to overcome the energy barrier. Moreover, there is an obvious homogenization (theory of G. Freyndlih) of charges throughout the cement-ash mixture and the disturbance of the aggregation stability of the system due to an excess of energy attraction, that is, overcoming the disjoining pressure (Deryagin-Landau-Ferway-Overbek theory [DLFO]) at the EMC effect. Because of this, the process of cementitious mixture coagulation and the intensive formation of the crystal lattice framework due to the formation of crystalline hydrates are intensified. 
With the above analysis, note that the mechanism of the EMC activation is increasing the strength of ionic attractions due to electrical charges and the appearance of the surface valence forces at their approach. These circumstances are one of the most decisive in the formation of coagulation structure of cement-ash gel and the hardening system associated with a gradual increase in the strength of interaction (coupling) of the structural elements belonging to the composition of growth-activated cement-ash binder.

\section{Conclusions}

First, a technique of experimental research was developed to work out effective ways to activate the cement-ash binder. To this end, a logical sequence that lies at the base of the research technique was adopted: (a) idea, (b) principle, (c) method, and (d) device.

The essence of the idea is to use the advantages of the polarizability of binder particles in an electric field to further its activation.

The principle lies in the simultaneous action of two factors on a particle: the electric field and the grinding process.

The method of binder activation involves a combination of two operations (processes of grinding and electric polarization) in a ball mill, that is, drum electropolarization mill.

The design features of the specially designed ball mill have been patented. The simultaneous impact on the particle of the electric field binder and mechanical grinding leads to high results, which for this reason, the combination of these two types of impacts effectively reveals the potential of the electric nature of the particle. The compressive strength of cement-ash stone activated by EMC processing in the drum electropolarization mill increased by $50-60 \%$ at a $30-40 \mathrm{~V}$, respectively. It was revealed that the EMC activation method is more efficient in the DC electric field than in the AC one. The positive results obtained from this research and experimental search are reflections of the correctness and appropriateness of the chosen search methodology through a logical sequence: idea, principle, method, and device.

\section{References}

Uderbayev S.S. Influence of the electromechanochemical activation on energetically active state of ash. Proceedings of the IX International Scientific- Practical Conference "Science and Education - 2006", Ukraine, Dnepropetrovsk, 2006. Vol. 10. p. 92-95.

Gusev B.V. Problems of creation of nanomaterials and development of nanotechnologies for construction. Nanotechnologies in Construction: scientific online magazine. Moscow: CNT "NanoStroitelstvo". 2009. No. 2. pp. 5-10. <http://www.nanobuild.ru>

Belov V.V., Smirnov M.A. Optimization of particle size distribution of raw mixes to make compressed cement-bonded concrete. Nanotechnologies in Construction: scientific online magazine. Moscow: CNT "NanoStroitelstvo." 2010. No. 2. pp. 7-19. State register. No. 0421000108. <http://www.nanobuild.ru>

Rybyev I.A. Construction Materials based on Binders: Artificial Construction Conglomerate. Textbook for high schools. M., HS. 1978.

Locher F.V., Rikharts B. Investigation of the Mechanism of Hydration of Cement. -M., SI, 1976. Volume 2.

Akhverdov I.N. Fundamentals of Concrete Physics. M. , Stroyizdat. 1981. - 464 pp.

Ratinov V.B., Ivanov F.M. Chemicals in Construction. M., Stroyizdat. 1969. - 200 pp.

Omarova K.I., Tussupbaev N.K., Mussabekov K.B. Tutorials on the measurement of zeta potential of disperse systems by method of electrophoresis. (For students of faculty of chemistry, Alma -Ata), ed. KSU, 1986, p. 19.

Voznessensky V.A. Statistical solutions to technological problems. Kishinyev, Map of Moldavenyaske, 1968, p. 232.

A. Zeidel. Simple estimates of measurement errors. -M. , Science, 1967.

Patent RK No. 7745. The drum electropolarization mill / Bissenov K.A., Akchabaev A.A., Uderbayev S.S., Akchabayev M.A.; publ. 03.12.2001, Bull.No. 12. 3 pp.

Provisional patent RK No. 7888. Mechano-electropolarization composition of binder. / Akchabayev A.A., Bissenov K.A., Uderbayev S.S.

Provisional patent RK No. 7890. The composition of wood-concrete mixture. / Akchabayev A.A., Bissenov K.A., Uderbayev S.S. Stated 28.06.1997. Published 16.08.1999, Bull. No. 8.

Akhverdov I.N. Basic Physics of Concrete. M. Stroyizdat, 1981. - 464 pp.

Akhverdov I.N. Acoustic concrete technology / ed. by corresponding member of the Byelorussian Academy of Sciences, Dr. of Techn. Sciences, Prof. I.N. Akhverdov. -M.: SI , 1976, 145 pp.

Bissenov K.A., Akchabayev A.A., Uderbayev S.S. Binder activation by polarization as a way to increase the strength of wood concrete. Reports of the Ministry of Science and Higher Education of the National Academy of Sciences of the Republic of Kazakhstan , No. 4, 1999. s. 60-65. 